\title{
EPIDEMIC RESILIENCE LABEL FOR A POST-COVID CITY (ERL Project)
}

\author{
Nuria Vallespín Toro (nvallespin@gmail.com). PhD Architect. \\ University of La Laguna. Spain. \\ Jorge Arribas Castañeyra (jarribasc@hotmail.com). PhD architect. \\ University of Las Palmas de Gran Canaria. Spain.
}

\begin{abstract}
The development of a label that evaluates the epidemic-resistance capacity of places of social exchange can be an invaluable tool in determining prevention policies on the one hand and social containment and distancing measures on the other. Policies that protect the health of citizens as much as possible while allowing develop human activities. The research project will work on the evaluation of the safety of buildings and urban spaces in cities in the context of a pandemic such as Covid-19 through the development of the so-called Epidemic Resilience Label. Passive site labelling measures will promote synergies for the development of the economy of this new normality. Citizens will choose the most protected sites; businesses will therefore want to improve their labeling and containment phases can be decided based on-site ratings.
\end{abstract}

Keywords: Built Environment, Epidemic, Resilience, Labelling, Rating

\section{1. - INTRODUCTION}

The increase in the world's population and the planet's carrying capacity brings pose a series of challenges for humanity. Challenges that will have to face the global crises that will occur with the increase in population. Climate, energy, food, economic and cultural crises. In this case, an epidemic crisis, which could be defined as a crisis of the human ecosystem due to an imbalance with respect to other organisms on the planet. In the history of humanity these crises have followed one another, famines, wars, plagues, and we have overcome them through scientific advances and cultural adaptations.

Everything points to the fact that these crises will occur more frequently, in the case of virus pandemics, the high density of population in cities, the rapid means of transport, and the invasion by human beings of ecosystems, among other factors, make us think that the fight against pandemics will not be a one-off event, but rather a new situation to which we will have to get used.

Therefore, we will need new scientific advances and new social behavior. Life in constant quarantine may be the new way of life. But this does not mean that social contacts should be reduced and the achievement of our well-being taken for granted. The current Covid-19 crisis can help us to understand in depth and recalibrate the real impact that buildings and urban space have and the role they play in the transmission of viral epidemics. As architects and urban planners we have the opportunity to analyse how our built environments affect the transmission of certain viral epidemics and pandemics. The built environment (BE) is the set of environments that we humans have built, including buildings, cars, roads, public transport, parks, etc. BE's act as transmitters of the spread of these diseases since they promote interactions between individuals, being in many cases focal points of viral exchange. 
We propose a method to manage the safety of built environments against diseases, an intuitive method for the population, which will be able to know through Epidemic Interactive Maps where to go and where not. Just like every morning we go to the weather report to decide whether to go to the beach or the shopping center or what clothes to wear, every morning we will see the risk of diseases and we will go to one place or another with one or another safety measure. We will live without fear, just used to some precautionary measures.

\section{2. - THE RESEARCH PROJECT}

The mobility restrictions that many countries have adopted have helped to contain the spread of Covid-19. These social distancing measures entail a multitude of impacts that unequally affect populations based on social, cultural, and economic factors. A better understanding of our built environment may be useful in decision-making and control mechanisms in the implementation of distancing and isolating measures, duration and limitation of occupation or transit density.

The ERL research project proposes the elaboration of Epidemiological Maps for a 'new normality' based on places, not people. One of the risks of the so-called ICTs (Information Technologies) in using them for population control to prevent the spread of diseases is the reduction or loss of freedom. This is an open discussion, considering the freedom as an essential pillar that should not be infringed. We believe that control by mobiles devices should not be the solution, and currently, organizations such as Human Rights Watch warn that the introduction of citizen surveillance systems that many countries such as China or South Korea are promoting, although they can help make better public health decisions, are strengthening a system of permanent surveillance of their citizens.

In the ERL project we are looking for a solution based on monitoring places, not people. Spatial analysis and its different degrees of connectivity will provide us with ad hoc information to reduce the potential for transmission through the BE. An assessment of the transmission probabilities in each location will be offered, both static and mobile, so that depending on the phases of a pandemic, transit through these locations will be authorized or recommended or not. It will be possible to decide where to go, what means of transport to use and the risk involved in those actions. The freedom of the citizen will be safeguarded by allowing everyone to decide on his or her actions, without fear of either the pathogen or government control.

Government control should be focused on places. We propose the requirement of compliance with certain minimum parameters according to the use and typology of each space, as a preventive measure. During the phases of the epidemic, we propose the opening of spaces, activities and movements depending on the security they offer, based on their label. It will be a Resilient Label, framed in 17 UN 2030 Agenda on Sustainable Development Objectives, specifically Objective 11: Make cities and human settlements inclusive, safe, resilient and sustainable.

The research project will propose the technical-sociological bases for this purpose, through a methodology that allows evaluating and classifying the built environment and 
its parameterization, study of the minimum requirements according to the activities carried out, study of the implementation of Epidemiological Maps for the control of quarantine phases, study of their optimization for a minimum impact on the economy and finally the ICT, Big data and Labelling contributions of the spaces to generate the epidemiological maps interactively. It is intended that this classification can be contained in existing tools and applications to complement these as support for decision-making about the epidemic, in real time, in an agile and updatable way.

Every year there is storms seasons, with its consequences, but this does not mean the paralysis of human activity. It is a fact to face, as well as possible future pandemics.

\section{3. - THE METHODOLOGICAL PROPOSAL}

The project aims to give a global vision, is overly broad and therefore ambitious. It is intended to be a starting point for future researches and practical developments. Built Environments are imbued with multiple meanings and capture the simultaneity of social experiences. From architecture to anthropology, the different disciplinary perspectives present in this series will investigate the often-overlapping layers that are part of the phases that are intended to be addressed. (Fig.1)

The research is subdivided into 6 phases, each of which will last one month. At the end of every phase, the results will be published in a scientific synthesis paper. The last paper will attempt to encompass the five previous phases as a global vision of the research and practical application.

Phase 1. - Contributions to the development of the label. Analysis of the BE.

-Format, values. Template. The determination of the assessment of the labels will be developed through technical-scientific criteria with evaluation of routes, contact areas, users, etc. These must be developed by architects, urban planners, engineers, and geographers.

\section{Phase 2. - Contributions to preventive measures.}

- Living and working patterns. Minimum requirements to places. Regulatory implementation.

\section{Phase 3. - Contributions to active policies. Urban dynamics.}

- Definition of confinement and phases according to the labelled spaces. Epidemiological maps. Study of social behavior in the face of these.

\section{Phase 4. - Preliminary study of the economic effects of the new policies.}

- Economic Optimization Measures produced by these dynamic Epidemiological Maps in relation to the more conventional methods of confinement. Analysis positive synergies created by the use of the label as a means of improving the competitiveness of the spaces.

Phase 5. - Big Data and Labelling. The big possibilities for labelling the BE. 
- Finally, for the applications, the applications will be developed with IT and an ICT environment that will allow the active implementation of all these measures.

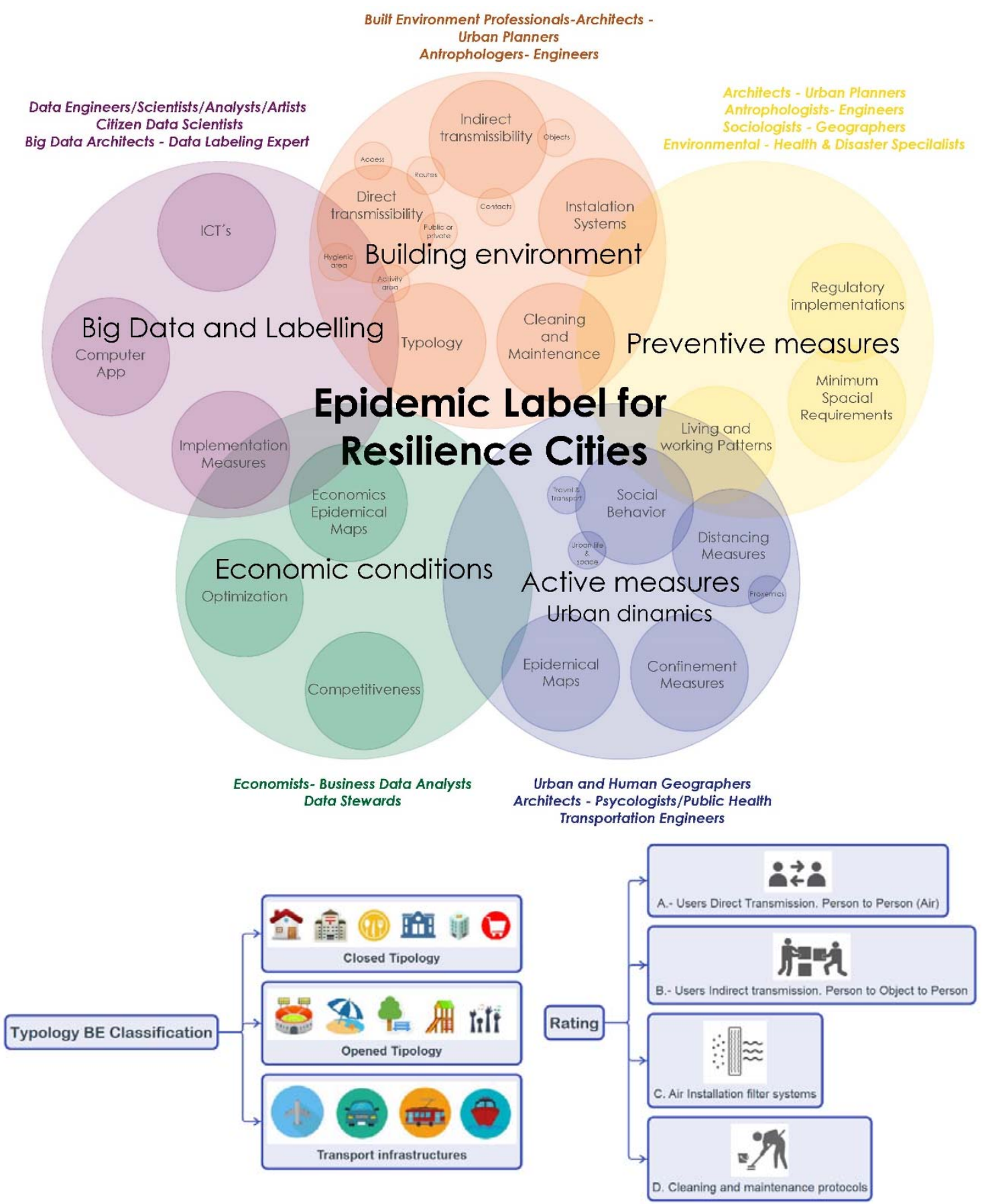

Fig. 1. Conceptual working plan for Epidemiological Label through the analysis of urban and socio-spatial measures and the transdisciplinary agents involved.

\section{4. - OBJECTIVES AND UTILITIES}

The objectives of this research are to serve as a basis for the development of the whole system explained above. Specifically:

-Definition of labels, parameters, and methods of obtaining them. 
-Creation of the city/territory map by means of the geolocation of all the labelled spaces.

The classification of the spaces according to an Epidemic Label can provide the population and managers of the epidemic with important spatial data in this phase, such as:

- Safe urban routes.

- Preferential walking destinations and outdoor activity (open spaces, parks, beaches, others) in each urban area, delimited by their carrying capacity to regulate population concentrations.

- Establish preferential places for walking or expansion for different age groups to segregate in separate spaces population groups whose contact may reactivate the chain of contagion.

-Define strategies and App's to alert the population of those places that are permitted, restricted and personal protection measures to be adopted.

- Interactive Maps can be complemented with infection sites focus maps of infection, thus further specifying the geographical scope of the action.

\section{CONCLUSIONS}

The Epidemic Label tool will provide a disease control that does not restrict people's individual freedom, while producing precise isolation measures that do not affect the entire economy but only the unprepared. Future development should also consider how to provide additional incentives for promoting construction and design of the built environment with passive and active measures to reduce lockdown periods. In other words, the research promotes a global resilience for cities to future viral epidemics or pandemics.

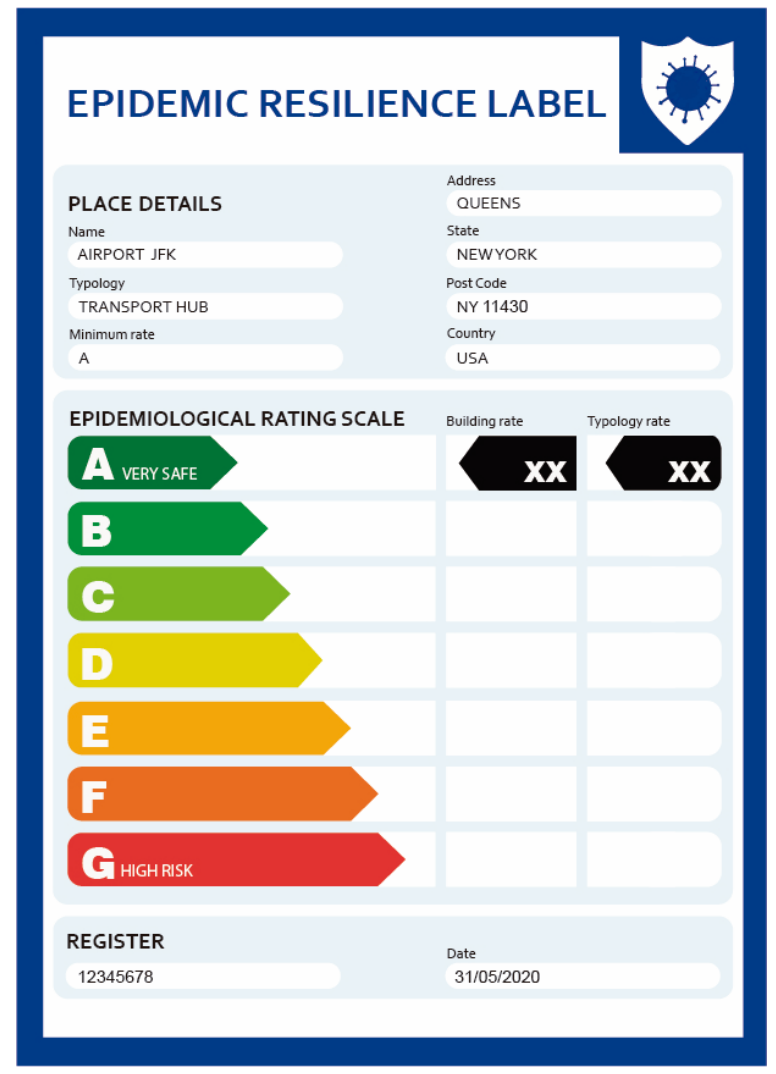


References:

- Braun, B. (January 01, 2009). Thinking the City through SARS: Bodies, Topologies, Politics. 250-266, in Ali, S. H., \& Keil, R. (2009). Networked Disease: Emerging Infections in the Global City. Hoboken: John Wiley \& Sons, Ltd.

- $\quad$ Bruns, D. P., Kraguljac, N. V., \& Bruns, T. R. (April 01, 2020). COVID-19: Facts, Cultural Considerations, and Risk of Stigmatization. Journal of Transcultural Nursing.

- Bordehore, C. Navarro, M. Herrador, Z., Fonfria, S. (April 01, 2020). Understanding COVID-19 spreading through simulation modeling and scenarios comparison: preliminary results. MedRxiv 2020.03.30.20047043; doi: https://doi.org/10.1101/2020.03.30.20047043

- Colomina, B. (2019). X-ray architecture. Zürich: Lars Müller publishers.

- Dietz, L., Horve, P. F., Coil, D. A., Fretz, M., Eisen, J. A., Van, D. W. K., \& Gilbert, J. A. (April 07, 2020). 2019 Novel Coronavirus (COVID-19) Pandemic: Built Environment Considerations To Reduce Transmission. Msystems, 5, 2.)

- Hall, E. T. (1966). The hidden dimension. New York, NY: Doubleday. (Spanish edition. Hall, E. T. (2005). La dimensión oculta. México, D.F: Siglo XXI)

- Perles Rosello, M.J. Sortino Barrionuevo, J.F, Cantarero Prados, F.J, Castro Noblejas, H., De la Fuente Roselló, A.L., Orellana Macías, J.M, Reyes Corredera, S. Miranda Páez, Jesús, Mérida Rodríguez, M. (2020): Propuesta metodológica para la elaboración de una cartografía de riesgo de COVID19 en entornos urbanos. Informe de investigación. Dpto. de Geografía, RIUMA Universidad de Málaga.

- Salama, A. M. (April 16, 2020). Coronavirus questions that will not go away: interrogating urban and socio-spatial implications of COVID-19 measures. Emerald Open Research, 2, 14.

- Sorokowska, A., Sorokowski, P., Hilpert, P., Cantarero, K., Frackowiak, T., Ahmadi, K., Alghraibeh, A. M., ... Stamkou, E. (January 01, 2017). Preferred Interpersonal Distances: A Global Comparison. Journal of Cross-Cultural Psychology, 48, 4, 577-592. 